\title{
80
}

\section{Bactérias e fungos benéficos na endosfera das plantas}

Julierme Zimmer Barbosa ${ }^{1}$

Rangel Consalter ${ }^{2}$

Fabiane Machado Vezzani3

Antonio Carlos Vargas Motta ${ }^{4}$

\section{Resumo}

No solo, a região da rizosfera, em comparação com a massa de solo, apresenta marcado contraste biológico, sendo um nicho de grande densidade e diversidade de microorganismos. Alguns fungos e bactérias benéficos ao desenvolvimento vegetal têm capacidade de colonizar o interior de plantas a partir do solo, conhecidos como organismos endofíticos. Possivelmente sejam as bactérias nodulíferas, com sua reconhecida capacidade de fixar $\mathrm{N}$ em leguminosas conhecidas. Bactérias não nodulíferas têm a capacidade de colonizar o interior das raízes das plantas por meio de regiões de crescimento, em seguida, podem ser carregadas via xilema rumo à parte aérea. Podem ser encontradas em todos os órgãos vegetais, todavia, poucos estudos têm analisado as populações que transitam no continuum solo-planta até atingir caules, folhas, flores, frutos e sementes. 0 último grupo de organismos endofíticos apresentado é o grupo dos fungos micorrízicos. Esses fungos caracterizam-se por constituírem um sistema de exploração do solo, paralelo ao sistema radicular que, com diâmetro extremamente reduzido, consegue minar um grande volume de solo com pequena alocação de C. Essa característica é extremamente benéfica para a aquisição de nutrientes, além de ser benéfica em condições abióticas adversas. Além disso, alguns fungos endofíticos benéficos também podem colonizar órgãos aéreos das plantas. As interações entre micro-organismos endofíticos e as plantas são altamente complexas, simultâneas e dependentes de uma série de fatores. Contudo, seu entendimento é de fundamental importância para a aplicação prática dos conhecimentos acerca de micro-organismos endofíticos em agrossistemas.

Palavras chaves: Rizosfera. Endofítico. Produção vegetal.

\section{Introdução}

Em 1904, Hiltner denominou de rizosfera a região adjacente às raízes que sofre influência direta de sua presença e que tem constituição microbiana diferenciada do solo distante das raízes (HARTMANN et al., 2008). O contraste biológico entre solo rizosférico e não rizosférico é marcante, o que pode ser avaliado pela relação entre a densidade das populações de organismos. Neste sentido,

\footnotetext{
1 Universidade Federal do Paraná, pesquisador de doutorado. Curitiba, Paraná, Brasil. barbosajz@yahoo.com.br (041) 3350-5648. Rua dos Funcionários, 1540, Bairro Juvevê, Curitiba, CEP 80035-050.

2 Universidade Federal do Paraná, pesquisador de mestrado. Curitiba, Paraná, Brasil. rangelconsalter@hotmail.com.br (041) 33505648. Rua dos Funcionários, 1540, Bairro Juvevê, Curitiba, CEP 80035-050.

3 Universidade Federal do Paraná, professora pesquisadora. Curitiba, Paraná, Brasil. vezzani@ufpr.br (041) 3350-5609. Rua dos Funcionários, 1540, Bairro Juvevê, Curitiba, CEP 80035-050.

$4 \quad$ Universidade Federal do Paraná, professor pesquisador. Curitiba, Paraná, Brasil. mottaacv@ufpr.br (041) 3350-5630. Rua dos Funcionários, 1540, Bairro Juvevê, Curitiba, CEP 80035-050.
} 
a abundância de bactérias na rizosfera pode ser 24 vezes a do solo adjacente, enquanto para fungos, actinobactérias e protozoários, esse aumento é da ordem de 12, 6,6 e 2,4 vezes, respectivamente (BOLTON et al., 1992).

A magnitude com que o sistema radicular afeta o solo circundante depende do fator considerado (mucilagem, perda de células radiculares, exsudatos, respiração, absorção de nutrientes móveis ou imóveis, compostos voláteis e água), variando na escala de sub- $\mu$ m até supra-cm (HINSINGER et al., 2009). De maneira geral, os compostos voláteis liberados pelas raízes se destacam por atingir a microbiota a maiores distâncias (HINSINGER et al., 2009; DENNIS et al., 2010).

Na rizosfera, ocorrem diferentes relações bióticas, incluindo a ação de micro-organismos decompositores, herbívoros, patógenos, predadores e simbiontes, constituindo-se em um nicho ecológico (KORANDA et al., 2011; EISENHAUER, 2012). Das relações ecológicas resultam muitos efeitos benéficos para as plantas, atuando direta ou indiretamente sobre sua nutrição, balanço hormonal e proteção contra organismos nocivos (HASHEM e ABO-ELYOUSR, 2011; ZABIHI et al., 2011).

Seguindo no continuum solo-planta, muitas bactérias e fungos que habitam a rizosfera também podem colonizar o interior das plantas, sendo comumente chamados de organismos endofíticos, conforme mostra a Figura 1 (BERG et al., 2005a; WAGG et al., 2008; REINHOL-HUREK; HUREK, 2011).

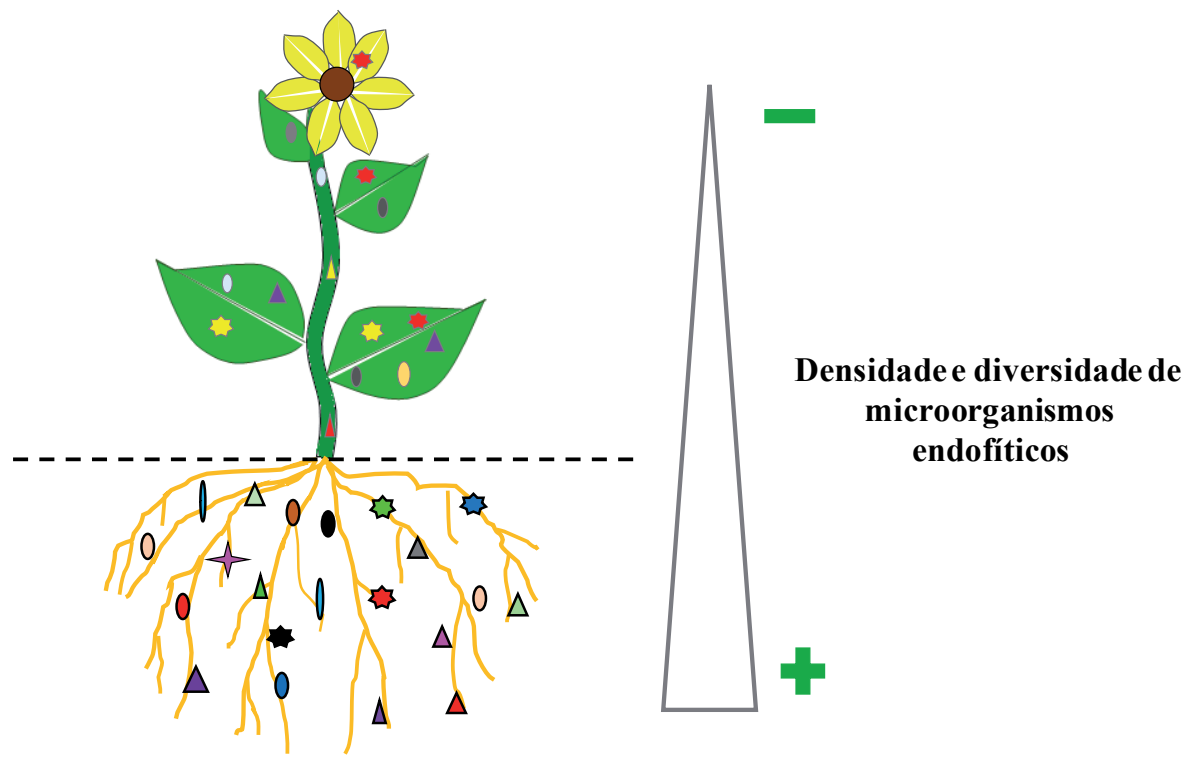

Figura 1: Representação esquemática do continuum solo/planta/micro-organismos Fonte: Adaptado de BRADER et al. (2014) pelos autores.

É conhecido que micro-organismos podem habitar a endosfera vegetal desde 1887, quando Galippe isolou diferentes micro-organismos de raízes e de caules de plantas de jardim e de vegetais encontrados no mercado, como cenoura e cebola (COMPANT et al, 2012). Atualmente, os avanços metodológicos e instrumentais têm permitido o estudo detalhado dos micro-organismos que entram pelo sistema radicular e colonizam todos os tecidos internos das plantas, com destaque para microorganismos que promovem a saúde das plantas (COMPANT et al., 2011). Todavia, endofíticos benéficos também são de interesse por causa do risco à saúde pública, uma vez que alguns podem ser patógenos para humanos (RYAN et al., 2009).

As interações entre micro-organismos endofíticos e as plantas são altamente complexas, simultâneas e dependentes de uma série de fatores. Contudo, seu estudo é de fundamental importância 
para a aplicação prática dos conhecimentos acerca de micro-organismos endofíticos em agrossistemas, o que tem despertado grande interesse em diversas áreas da ciência. Dessa forma, esta revisão de literatura tem como objetivo buscar o estado da ciência das interações entre micro-organismos endofíticos e plantas, visando contribuir para a difusão do conhecimento do meio endofítico como hábitat para micro-organismos benéficos.

\section{Micro-organismos endofíticos}

\section{Bactérias}

Em condições de baixa disponibilidade de $\mathrm{N}$ no solo, algumas plantas liberam compostos orgânicos, como voláteis do tipo flavonoides, que atraem algumas bactérias e actinobactérias para o sistema radicular (SVISTOONOFF et al., 2004). Posteriormente, os micro-organismos penetram por pelos radiculares ou pela epiderme e formam estruturas denominadas nódulos. Ambas as bactérias possuem a enzima nitrogenase (encontrada também em bactérias não endofíticas), a qual converte o $\mathrm{N}$ atmosférico em formas amoniacais, que são transferidas para as plantas em troca de açúcares provenientes do processo fotossintético (PAWLOWSKI, 2002; COOPER, 2004).

As bactérias da família Rhizobiaceae (alfa-proteobacteria) dos gêneros Rhizobium, Bradyrhizobium, Sinorhizobium, Mesorhizobium, Allorhizobium e Azorhizobium - comumente chamadas de rizóbios - são encontradas em nódulos radiculares de plantas da família Fabaceae e em Parasponia andersonii (planta não leguminosa) (VIEIRA, 2007). A interação de plantas e bactérias nodulíferas resulta em adição de $\mathrm{N}$ nos agrossistemas em quantidades variáveis, sendo destaque, por exemplo, para a produção de soja (Glycine max L.), onde a inoculação de estirpes selecionados possibilitam a fixação de até $176 \mathrm{~kg} \mathrm{ha}^{-1}$ ano $^{-1}$ (HERRIDGE et al., 2008), o que permite o cultivo praticamente sem adição de $\mathrm{N}$-fertilizante. Esse processo natural benéfico contribui para que a soja seja a cultura agrícola economicamente mais importante na América (FAO, 2013). Todavia, é preciso destacar que um gênero de beta-proteo-bacteria, chamado Burkholderia, forma nódulos em fabáceas, porém são chamados de beta-rizóbios (BARRETT; PARKER, 2006).

Em relação às actinobactérias, a especificidade é maior, pois se restringe a apenas 25 gêneros de plantas, predominantemente árvores e arbustos lenhosos, que têm as raízes colonizadas pelo gênero de actinobactérias Frankia (PAWLOWSKI, 2002). Por outro lado, artificialmente, Senthilkumar et al. (2009) utilizaram auxinas sintéticas para induzir a nodulação em arroz (Oryza sativa L.), planta da família Poaceae, com isolado de Methylobacterium sp. que, além de fixar N, também produz auxinas e citocininas.

Algumas bactérias não nodulíferas podem entrar nas raízes, sobretudo através da região entre a epiderme e a coifa, pelos radiculares ou por espaços que aparecem durante a emergência de raízes secundárias (Figura 2) (JAMES et al., 2002). Após a entrada das bactérias nas raízes, a colonização das células do córtex é a forma mais comum de ocupação endofítica; em oposição, para atingir a região central da raiz é necessário passar pelas células da endoderme. Isso ocorre quando as bactérias secretam enzimas que degradam a parede celular das células da endoderme ou quando passam por espaços que aparecem na endoderme durante a emergência de raízes secundárias (JAMES et al., 2002). Conforme Hallmann (2001) observa-se população bacteriana no interior das raízes com densidade de aproximadamente $10^{5}-10^{7}$ unidades formadoras de colônias por grama de tecido (UFC g-1). 

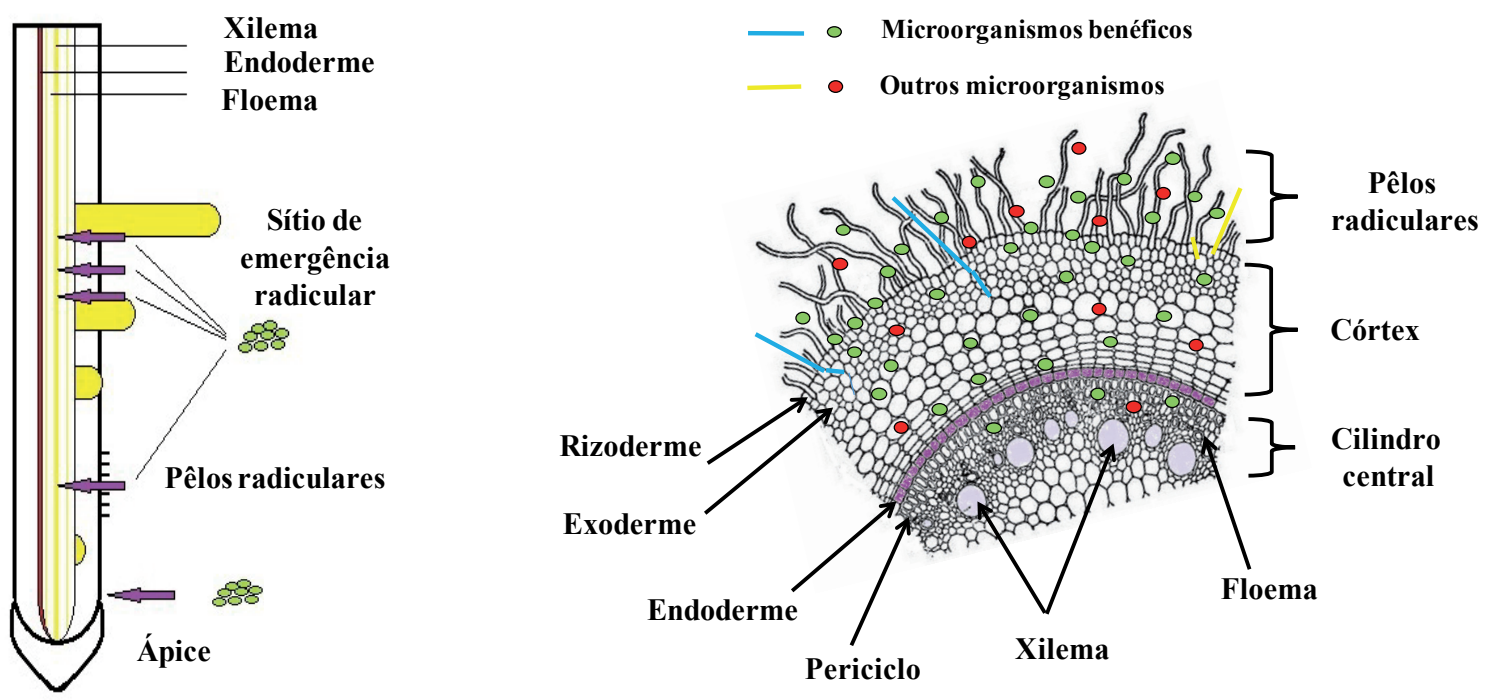

Figura 2: Vias de acesso dos micro-organismos do solo para a endosfera das plantas Fonte: Adaptado de Compant et al.(2010) pelos autores.

A região central da raiz contém os vasos do xilema, que são responsáveis pelo transporte de água e nutrientes para a parte aérea da planta. Com o aprimoramento metodológico-instrumental, tem-se verificado que as bactérias que atingem o cilindro central também utilizam passivamente essa via de transporte (JAMES et al., 2002). A capacidade de mobilidade e de adaptação bacteriana, associada ao fluxo transpiratório e ao comportamento do xilema como livre condutor possibilitam a chegada das bactérias até órgãos vegetativos e reprodutivos (JAMES et al., 2002; COMPANT et al., 2011). Em tempo, a sobrevivência bacteriana de forma livre no ambiente endofítico requer características diferenciadas, como: presença de estruturas locomotoras (flagelos); secreção de enzimas diversas; mecanismos de desintoxicação e capacidade de metabolizar os produtos provenientes da fotossíntese e do metabolismo secundário das plantas (RASCHE et al., 2009; REINHOL-HUREK; HUREK, 2011).

Estudos têm avaliado as populações de bactérias que transitam no continuum solo-planta (solo, raiz, caule, folha, flor e fruto), sobretudo aquelas que apresentam características que podem beneficiar as plantas (COMPANT et al., 2008). As colônias de bactérias endofíticas nos tecidos caulinares e foliares apresentam populações com densidade de $10^{3}-10^{4}$ UFC g-1 (HALLMANN, 2001). Já a colonização dos órgãos reprodutivos é ainda mais restrita, com densidade bacteriana na ordem de $10^{2}-10^{3}$ UFC g ${ }^{-1}$, demonstrando que somente micro-organismos altamente especializados têm competência para colonizar esses nichos. A ciência acerca das funções das bactérias sobre a formação e o desenvolvimento dos órgãos reprodutivos é extremamente limitada, porém, alguns gêneros de bactérias, como Pseudomonas e Bacillus, encontrados nesses órgãos (COMPANT et al., 2011), possuem habilidades que promovem a saúde dos vegetais (HARDOIM et al., 2008). É possível que sementes, contendo bactérias endofíticas internamente, atuariam como fonte de inóculo específico para as plantas geradas a partir dessas sementes, provavelmente, passando de geração em geração (JOHNSTON-MONJE e RAIZADA, 2011).

As bactérias endofíticas não nodulíferas podem amplificar a saúde dos vegetais, por meio de mecanismos de ação nutricional, hormonal ou de proteção contra patógenos e herbívoros (HARDOIM et al., 2008). O principal efeito nutricional é a fixação de $N$, que pode suprir uma parte das exigências 
das plantas (HERRIDGE et al., 2008). Considerando as principais gramíneas (Poaceae) cultivadas (arroz, cana-de-açúcar, milho e trigo), Barbosa et al. (2012) reportam que a cana-de-açúcar apresenta alta eficiência simbiótica com bactérias diazotróficas, sendo possível obter altas produtividades sem a aplicação de adubo nitrogenado, similarmente à soja (Fabaceae). Já os efeitos hormonais ocorrem em razão da produção e liberação de hormônios pelas bactérias, tais como: auxinas, citocininas e giberelinas, as quais têm efeito estimulante sobre o metabolismo vegetal. Em adição, algumas bactérias utilizam precursores da síntese de etileno nas plantas, inibindo o seu acúmulo e assim, proporcionando efeito benéfico para as plantas (HARDOIM et al., 2008). Quanto à proteção contra patógenos, essa ocorre de forma direta, em decorrência da produção de substâncias supressoras, e indiretamente pela melhoria sistêmica da saúde vegetal promovida por mecanismos bacterianos com ação hormonal ou nutricional (BERG et al., 2005a).

$\mathrm{O}$ fato de muitas estirpes de bactérias habitarem tanto a rizosfera como o interior das plantas denota sua ampla capacidade de colonização, não obstante, podem atuar como oportunistas em seres humanos (BERG et al., 2005b; RYAN et al., 2009). Com esse potencial, podem-se destacar os gêneros Burkholderia, Enterobacter, Herbaspirillum, Pseudomonas e Stenotrophomonas, que também melhoram a saúde vegetal. Os patógenos oportunistas são responsáveis por causar infecções em pessoas com baixa imunidade, como portadores do vírus HIV, de doenças crônicas ou sob longo período em tratamento com antibióticos (BERG et al., 2005b). Dessa forma, o desenvolvimento de produtos biológicos, visando à utilização na agricultura, deve considerar esses fatores, para prevenir que alimentos de origem vegetal sejam fontes de inóculo bacteriano para seres humanos ou, ainda, para evitar possíveis interações genéticas com populações nativas do continuum solo-planta (RYAN et al., 2009).

No Brasil, insumos biológicos à base de bactérias nodulíferas em leguminosas estão bem difundidos, porém, para bactérias não nodulíferas, o uso na agricultura é recente e ainda pouco utilizado (LOPES, 2009; HUNGRIA, 2011). Entretanto, na América do Norte e Europa, essa realidade é diferente, pois nessas regiões são comercializados diversos produtos, com destaque para aqueles que visam à nutrição das plantas (BHATTACHARJEE et al., 2008) e ao biocontrole (BERG, 2009), inclusive insumos com várias espécies de bactérias, como o fungicida biológico Companion ${ }$, com Bacillus subtilis GB03, outro B. subtilis, B. lichenformis e B. megaterium.

A utilização de bactérias endofíticas também se mostra extremamente útil na fitorremediação de áreas contaminadas ou degradadas. Estudos recentes apontam que um ambiente contaminado com um determinado poluente poderá ser fitorremediado com mais eficiência se as plantas forem inoculadas com endofíticos capazes de degradar o contaminante. Nesse sentido, NEWMAN e REYNOLDS (2005) observam que a inoculação de plantas com uma bactéria modificada (VM1330) aumentou sua tolerância ao tolueno em 10 vezes, ao mesmo tempo em que reduz em mais de 50 \% e emissão desse contaminante pela parte aérea das plantas.

\section{Fungos}

As interações simbióticas entre o sistema radicular das plantas e alguns fungos são comumente referenciadas como associações micorrízicas. Nessas interações, o micélio do fungo colonizando a raiz se estende para o solo e absorve água e nutrientes. Por outro lado, os fungos se beneficiam ao utilizar em seu metabolismo produtos fixados pelo processo fotossintético das plantas (WANG; QIU, 2006). 
Os fungos micorrízicos arbusculares (FMA) são os tipos mais encontrados nas espécies vegetais, o que engloba grande parte dos cultivos de interesse agrícola, visto que a colonização das raízes hospedeiras ocorre de modo intracelular (Tabela 1) (WANG; QIU, 2006). Em algumas plantas arbóreas, como pinus e eucalipto, a associação ocorre com fungos ectomicorrízicos (FE), na qual o micélio penetra entre as células da epiderme e do córtex da raiz (CAIRNEY, 2011). Em adição aos FMA e $\mathrm{FE}$, o sistema radicular pode ser hospedeiro para outros fungos, incluindo os fungos endofíticos "dark septate" (FEDS), que apresentam exploração endofítica inter e intracelular (JUMPPONEN, 2001). Não obstante, plantas associadas com FMA ou FE podem ter simultaneamente o sistema radicular colonizado por FEDS (WAGG et al., 2008).

Tabela 1: Levantamento de espécies dos quatro maiores grupos de plantas terrestres quanto à micorrização (WANG; QIU, 2006)

\begin{tabular}{ccccc}
\hline Grupo & $\begin{array}{c}\text { Número de } \\
\text { espécies } \\
\text { pesquisadas }\end{array}$ & $\begin{array}{c}\text { \% de espécies } \\
\text { com micorrização } \\
\text { obrigatória }\end{array}$ & $\begin{array}{c}\text { \% de espécies } \\
\text { com micorrização } \\
\text { facultativa }\end{array}$ & $\begin{array}{c}\text { \% de espécies não } \\
\text { micorrízicas }\end{array}$ \\
\hline Briófitas & 143 & 42 & 4 & 54 \\
Pteridófitas & 426 & 43 & 9 & 47 \\
Angiospermas & 2.964 & 72 & 13 & 14 \\
Gimnospermas & 84 & 99 & 1 & 0 \\
Total & 3.617 & 68 & 12 & 20 \\
\hline
\end{tabular}

Fonte: Elaboração dos autores.

As plantas micorrizadas têm maior demanda energética no sistema radicular, contudo, essa demanda pode ser compensada quando a fotossíntese da planta aumentar em decorrência da maior aquisição de nutrientes e água (KASCHUK et al., 2009; GABRIEL-NEUMANN et al., 2011). Destaca-se o grupo das gimnospermas, que têm 99\% das espécies como micorrízicas obrigatórias, enquanto, nas angiospermas, cerca de 72 \% das espécies têm micorrização obrigatória. Dessa forma, pode-se dizer que, para a maioria das espécies cultivadas, a simbiose micorrízica é intrínseca.

O mecanismo de desenvolvimento das associações micorrízicas de FE e FMA é um processo complexo. De maneira geral, a baixa fertilidade do solo favorece o desenvolvimento pleno e a alta fertilidade restringe a colonização radicular, pois nessa condição, a colonização micorrízica se torna um gasto de $\mathrm{C}$ desnecessário (TRAJANO et al., 2001; KIRIACHECK et al., 2009). Já em relação ao FEDS, a condição de fertilidade não parece ter grande efeito regulatório (JUMPPONEN, 2001).

Associações micorrízicas podem contribuir para outras formas de simbioses entre micro-organismos e vegetais (CHALK et al., 2006). O processo de fixação de $\mathrm{N}$, desenvolvido por bactérias nodulíferas em associação com raízes de fabáceas, em alguns casos, dependendo das espécies de bactérias e plantas envolvidas, pode ser estimulado quando as plantas estão inoculadas com isolados compatíveis de fungos micorrízicos (XAVIER; GERMIDA, 2003). Em adição, a interação com as bactérias que vivem livremente no interior dos tecidos das plantas também pode ser beneficiada pelas micorrizas (SALA et al., 2007). Esse benefício é resultante da melhor nutrição mineral das plantas micorrizadas, ou de interações diretas entre fungos micorrízicos e bactérias fixadoras, fato demonstrado quando os estudos utilizam elementos marcados, como o isótopo ${ }^{15} \mathrm{~N}$, que permite quantificar quanto de $\mathrm{N}$ é fornecido diretamente pelos microsimbiontes (CHALK et al., 2006).

Alguns isolados de fungos micorrízicos apresentam efeitos benéficos para as plantas em condições que vão além da carência de elementos nutrientes. Condições adversas de disponibilidade de água, pH, compactação, contaminação e temperatura do ambiente são fatores abióticos nos quais a 
associação micorrízica pode favorecer as plantas (MANDYAM; JUMPPONEM, 2005; GARG; CHANDEL, 2011). Em relação aos fatores bióticos, alguns estudos demonstram que plantas micorrizadas são menos susceptíveis ao ataque de patógenos e herbívoros (GANGE et al., 2005; MANDYAM; JUMPPONEM, 2005; HOFFMANN et al., 2011; VERESOGLOU; RILLING, 2012). Os efeitos supracitados podem resultar em melhoria sistêmica da saúde vegetal, conferida pela melhor nutrição vegetal decorrente da associação micorrízica ou por características intrínsecas aos próprios fungos, sem efeito direto sobre os hospedeiros, como, por exemplo, a retenção de metais pesados nos micélios (GARG; CHANDEL, 2011). Entretanto, deve ser destacado que o comportamento dos vegetais varia em função de condições ambientais e em nível do isolado de fungo, portanto, em alguns casos pode não ser benéfica, verificando-se até mesmo efeito negativo da inoculação (XAVIER; GERMIDA, 2003).

Os benefícios que os fungos micorrízicos podem trazer para as plantas desperta o interesse para agricultura. GEWIN (2010) inclui esses organismos no pacote da chamada nova revolução verde ou revolução subterrânea, juntamente com interações com bactérias fixadoras de $\mathrm{N}$, plantas com capacidade de resistir à seca e ao Al tóxico presente em solos muitos ácidos. Por outro lado, plantas micorrizadas com certos isolados de fungos pode promover o crescimento de plantas em solos contaminados. SIQUEIRA et al., (1999) observaram que a inoculação de cinco espécies de plantas arbóreas favoreceu a produção vegetal, apesar de não aumentar a extração de Cd e Zn do solo contaminado. Isso é relevante por possibilitar que ocorra incorporação de C no solo contaminado ou, igualmente útil, em áreas degradadas. Se não ocorre variação das concentrações dos contaminantes nas plantas micorrizadas, pode ser em função da retenção de metais nas hifas fúngicas (CABRAL et al., 2010). Por outro lado, pode ocorrer, em algumas interações, elevação no acúmulo de metais na parte aérea das plantas, como observado por SILVA et al. (2006) para $\mathrm{Cu}, \mathrm{Pb}, \mathrm{Zn}$ e Cd em braquiária decumbens.

A aquisição de produtos biológicos com fungos micorrízicos é possível em diversos países (RODRÍGUES-ROMERO; JAIZME-VEJA, 2007; CORKIDI et al., 2009; FERNÁNDEZ et al., 2011), com produtos como o MycoApply ${ }^{\circledR}$ Liquid Endo, vendido nos EUA, ou o MycoForce ${ }^{\circledR}$ Endo and Ecto Transplanter, vendido na Inglaterra, que contêm 4 (arbusculares) e 15 (8 arbusculares e 7 ectomicorrízicas) espécies de fungos micorrízicos, respectivamente. Já no Brasil, o uso dessas tecnologias, em grande escala, ainda não é uma realidade. Contudo, em nível de pesquisa, a produção de inoculante com fungos micorrízicos está avançada (Figura 3) (ROSSI, 2006; CZERNIAK; STÜRMER, 2014).
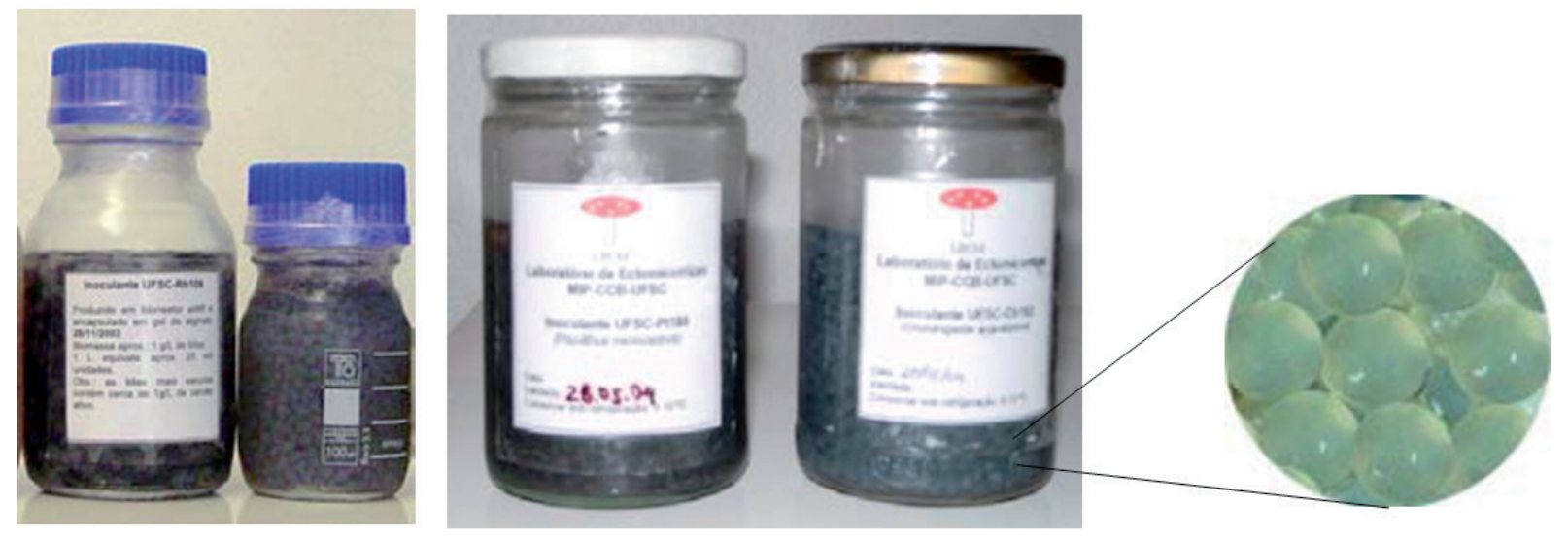

Figura 3: Lotes de inoculantes de fungos ectomicorrízicos encapsulados em gel de alginato de cálcio (ROSSI, 2006). Fonte: Elaboração dos autores. 
Alguns fungos encontrados no solo podem colonizar os órgãos aéreos das plantas (SCHULTZ e BOYLE, 2005; LUCERO et al., 2011). A colonização ocorre basicamente durante a germinação das sementes ou por esporos fúngicos transportados pelo vento. Na germinação das sementes, os fungos podem penetrar diretamente nas estruturas primárias das plântulas que são emitidas ainda no solo, ou já estarem dentro das sementes (transmissão vertical). Na situação em que esporos vêm pelo vento, a colonização ocorre após a germinação deles sobre a superfície dos órgãos aéreos da planta, com a penetração do micélio via lenticelas, estômatos ou diretamente pelo espaço intercelular (SCHULTZ e BOYLE, 2005; LUCERO et al., 2011).

Esses fungos endofíticos podem beneficiar o crescimento das plantas, principalmente em condições de cultivo estressantes, por meio da promoção do metabolismo vegetal (RODRIGUEZ et al., 2008). Além da aplicação para a agricultura, os fungos endofíticos têm despertado o interesse para a remediação de solos contaminados por promoverem o crescimento vegetal nessas condições extremas. Com essa perspectiva, SOLEIMANI et al. (2010) verificaram que fungos contidos em sementes de poáceas (Festuca ssp.) contribuem para que as plantas cresçam em solo contaminado com Cd. Já Deng et al. (2013) demonstraram que canola inoculada com fungo endofítico resistente ao Cd e ao $\mathrm{Pb}$ aumenta o crescimento das plantas em condição de solo contaminado, assim contribuindo para a fitorremediação desses metais pesados.

\section{Visualização e identificação de micro-organismos endofíticos}

A colonização do tecido vegetal por alguns micro-organismos endofíticos benéficos pode resultar no aparecimento de estruturas visíveis a olho nu (Figura 4). Nesse sentido, pode se dizer que os nódulos em raízes de soja e outras leguminosas, formados devido à colonização com bactérias fixadoras de $\mathrm{N}$, são as estruturas mais conhecidas (SVISTOONOFF et al. 2004). Por outro lado, ROSSI (2006) e SULZBACHER (2010) reportam a visualização de estruturas de fungos ectomicorrízicos (hifas e corpos de frutificação superficiais ou subterrâneos) associados com pínus e eucalipto. Contudo, para visualizar de forma detalhada (variável de acordo com a instrumentação e técnicas utilizadas) tanto bactérias como fungos na endosfera, é necessário utilizar microscópios (COMPANT et al., 2011).
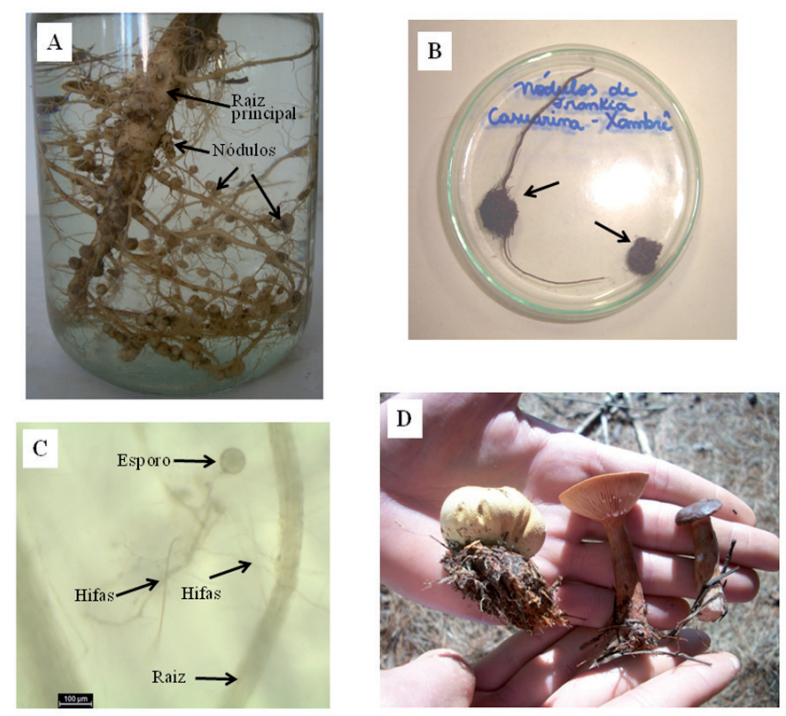

Figura 4: Visualização de nódulos e associações micorrízicas. $A=$ nódulos em feijoeiro; $B=$ nódulos de actinorríza em Casuarina ssp.; C = associação micorrízica em azevém (com auxílio de microscópio); D = corpos de frutificação de fungos ectomicorrízicos coletados em reflorestamento de Pinus taeda.

Fonte: Elaboração dos autores). 
Em microscópios ópticos, as visualizações de micro-organismos endofíticos são realizadas, na maior parte, por causa do uso de corantes que podem tingir de forma diferenciada os tecidos vegetais e os micro-organismos. Porém, com esse tipo de microscopia, tem-se dificuldade para diferenciar as bactérias dos constituintes celulares; além disso, pode apresentar alto efeito do segundo plano nas imagens. Contudo, para estudos de interações microrrízicas, são mais úteis, por causa do tamanho das estruturas fúngicas, relativamente maiores que as bactérias. Por outro lado, microscópios de fluorescência têm facilitado a visualização de micro-organismos endofíticos (THOMAS; REDDY, 2013). Vale lembrar que a fluorescência ocorre quando uma substância é exposta à radiação com determinado comprimento e emite radiação num comprimento de onda maior. Por exemplo, exposição de água tônica à radiação com comprimento de onda de $380 \mathrm{~nm}$ e emissão de fluorescência da quinona (componente da água tônica) em 450 nm (LAKOWICZ, 2006). Assim, os microscópios de fluorescência são similares aos microscópios ópticos, no que tange à capacidade de aumento, contudo, são equipados com lâmpadas ou laser (fonte de radiação) e filtros para selecionar os comprimentos de onda de interesse emitidos na forma fluorescente. A visualização ocorre como resultado da fluorescência de substâncias que compõem o micro-organismo e de corantes ou provas moleculares que ficam retidos nas estruturas dos micro-organismos (CARD et al., 2013). Em tempo, os microscópios eletrônicos, em função da alta capacidade de aumento ( $>10.000 x$ ), são muito úteis para estudar os micro-organismos endofíticos (THOMAS; REDDY, 2013).

Estudando meristemas da parte área de banana, THOMAS; SEKHAR (2014) reportam, por meio de fotografias e vídeos, em microscópico óptico e microscópio de fluorescência, a colonização do espaço intracelular por bactérias. Os vídeos são ferramentas bastante poderosas, uma vez que permitem reproduzir a movimentação das bactérias entre e dentro das células, com destaque para os vídeos em microscópio de fluorescência. Já COMPANT et al. (2008) aplicaram um isolado da bactéria endofítica benéfica às plantas (Burkholderia phytofirmans PSJN) na rizosfera de videiras e, por meio da fluorescência característica do isolado bacteriano, visualizaram sua capacidade de colonização do local de aplicação até as células dos tecidos radiculares, caulinares, florais e frutíferos. Já COMPANT et al. (2011) registraram a fluorescência de bactérias vivendo em estruturas internas de flores, frutos e sementes de videira. Nesse estudo, os autores utilizaram provas moleculares específicas para determinados gêneros ( $P$ seudomonas spp., Firmicutes, Bacillus) de bactérias, diferenciando-os em função do tipo de fluorescência característico para cada gênero. Outro tipo de estudo com provas moleculares fluorescentes consiste na visualização de bactérias vivas com fluorescência verde e amarela, enquanto bactérias mortas são visualizadas com fluorescência vermelha (THOMAS; REDDY, 2013). No mesmo sentido, VÁGI et al. (2014) visualizaram diferentes fungos endofíticos em raízes de milho, utilizando marcadores específicos. Essas pesquisas demonstram como o estudo do comportamento de micro-organismos na endosfera vegetal tem gerado ricas informações nos últimos anos, graças ao uso de ferramentas potentes de visualização.

Quanto à identificação dos micro-organismos endofíticos, as técnicas microbiológicas convencionais possuem uma forte limitação no fato de não detectarem organismos não cultiváveis (HANDELSMAN, 2004). Assim, a caracterização molecular, permitindo avaliar também micro-organismos não cultiváveis, revoluciona o estudo das interações entre plantas e micro-organismos (RAJENDHRAN; GUNASEKARAN, 2008). Atualmente, com o advento da caracterização molecular, é possível determinar a composição da comunidade bacteriana diretamente do material, sem necessidade de nenhum tipo de cultivo.

Utilizando técnicas moleculares modernas, é possível a observação da composição da microbiota dos ambientes rizo e endosférico de plantas, bem como o efeito de fatores bióticos e abióticos 
nas populações desses micro-organismos. MENDES et al., (2011) identificaram, a partir de amostras de solo rizosférico, genes e táxons de bactérias-chave na supressão de fungos patógenos de raízes de beterraba. Nesse sentido, BERENDSEN et al. (2012) revisam a importância da microbiologia rizosférica na saúde da planta, bem como os efeitos de solo e planta na estrutura da comunidade da microbiota da rizosfera. Ainda, NOVAIS et al. (2010) pontuam que a técnica molecular baseada em amplificação de uma sequência específica do DNA, com posterior observação das diferenças por meio de eletroforese em gel com gradiente de desnaturação (PCR-DGGE), possui aplicabilidade na determinação da pureza genética e na discriminação de de FMAs. Essas mesmas técnicas também possibilitam a caracterização molecular espécies de isolados de rizóbios (CHAGAS JUNIOR et al., 2009). Na endosfera, ABREU-TARAZI et al. (2009) verificaram a presença de bactérias endofíticas colonizando os tecidos das raízes e folhas de abacaxi. Técnicas de caracterização molecular possibilitaram aos autores indicarem diferenças entre as comunidades bacterianas de cada órgão da planta, bem como diferenças na estrutura de populações específicas entre os órgãos da planta.

\section{Considerações Finais}

A utilização de micro-organismos endofíticos para amplificar a produção vegetal se caracteriza como uma ferramenta com grande potencial de uso, com diferentes objetivos, envolvendo agricultura, fitorremediação de áreas contaminadas e a revegetação de áreas degradadas. Embora seja crescente o interesse por fungos micorrízicos e por bactérias de vida livre no meio endofítico, o uso ainda é reduzido quando comparado ao uso de bactérias nodulíferas na forma de inoculantes. Contudo, é de se esperar que cada vez mais fiquem disponíveis novas tecnologias para a inoculação microbiana em plantas, sobretudo no setor agrícola. Destaque-se, ainda, que, atualmente, com o uso de técnicas avançadas de biologia molecular associada ao uso de técnicas microscópicas é possível o estudo aprofundado da endosfera das plantas como hábitat microbiano e para seleção de micro-organismos. Adicionalmente, essas técnicas podem ser muito úteis para estudar como as interações entre micro-organismos endofíticos podem influenciar a saúde das plantas, aspecto que é menos conhecido, mas incrivelmente fascinante.

\section{Beneficial bacteria and fungi in plant endosphere}

\section{Abstract}

In soil, rhizosphere region compared to the mass of soil has marked biological contrast; a great density and diversity niche of microorganisms. Some fungi and bacteria that are beneficial to plant growth are able to colonize the interior of plants from the soil, known as endophytic organisms. It is likely to be the nodulating bacteria, with its recognized ability to fix nitrogen in legumes, are the most popular. Non-nodulating bacteria have the ability to colonize the interior of plant roots through growth regions and then may be loaded via xylem towards the shoot. They can be found in all plant organs; however, few studies have examined populations that travel in the soil-plant continuum to stems, leaves, flowers, fruits and seeds. The last group of endophytic organisms shown is the mycorrhizal fungi, these are characterized as an operating system parallel to the root system, with extremely small diameter that can undermine a large volume of soil with small allocation of $\mathrm{C}$. Besides being extremely beneficial in the acquisition of nutrients, it may also be beneficial in adverse abiotic conditions. 
Furthermore, some beneficial endophytic fungi can colonize aerial plant organs. The microbiological interactions that occur in endosfera are highly complex, simultaneous and dependent on a number of factors, so their understanding is crucial to the practical application of knowledge about endophytic microorganisms in agroecosystems.

Keywords: Rhizosphere. Endophytic. Plant production.

\section{Referências}

ABREU-TARAZI, M. A.; NAVARRETE, A. A.; ANDREOTE, F. D.; ALMEIDA, C. V.; TSAI, S. M.; ALMEI$D A, M$. Endophytic bacteria in long-term in vitro cultivated "axenic" pineapple microplants revealed by PCR-DGGE. World Journal of Microbiology and Biotechnology, v.26, p.555-560, 2009. Disponível em:< http://link.springer.com/article/10.1007\%2Fs11274-009-0191-3 > . Acesso em: 31 ago. 2015.

BARBOSA, J. Z.; CONSALTER, R.; MOTTA, A.C. V. Fixação biológica de nitrogênio em Poaceae. Evidência, Joaçaba, v.12, n.1, p.7-18, jan/jun. 2012. Disponível em:< http://editora.unoesc.edu.br/ index.php/evidencia/article/view/1811/pdf>. Acesso em: 31 ago. 2015.

BERENDSEN, R. L.; PIETERSE, C. M. J.; BAKKER, P. A.H. M. The rhizosphere microbiome and plant health. Trends in Plant Science, v.8, n.17, p.478-486, ago. 2012. Disponível em:< http://www. ncbi.nlm.nih.gov/pubmed/22564542>. Acesso em: 31 ago. 2015.

BARRETT, C. F.; PARKER, M .A. Coexitence of Burkholderia, Cupriavidus, and Rhizobium sp. nodule bacteria on two Mimosa ssp. in Costa Rica. Applied and Environmental Microbiology, Washington, v.72, n.2, p.1198-1206, fev. 2006. Disponível em: < http://www.ncbi.nlm.nih.gov/pmc/articles/ PMC1392967/> Acesso em: 31 ago. 2015.

BHATTACHARJEE, R. B.; SING, A.; MUKHOPADYAY, S. N. Use of nitrogen-fixing bacteria as biofertilizer for non-legumes: prospects and challenges. Applied Microbiology and Biotechnology, Heidelberg, v.80, n.2, p.199-209, ago. 2008. Disponível em: <http://link.springer.com/article/10.1007\%2Fs00253-008-1567-2/fulltext.html>. Acesso em: 31 ago. 2015.

BERG, G.; KRECHEL, A.; DITZ, M.; SIKORA, R. A.; ULRICH, A.; HALLMANN, J. Endophytic and ectophytic potato-associated bacterial communities differ in structure and antagonistic function against plant pathogenic fungi. FEMS Microbiology Ecology, Malden, v.51, n.2, p.215-229, jan. $2005 a$. Disponível em: <http://onlinelibrary.wiley.com/doi/10.1016/j.femsec.2004.08.006/pdf>. Acesso em: 31 ago. 2015.

BERG, G.; EBERL, L.; HARTMANN, A. The rhizosphere as a reservoir for opportunistic human pathogenic bacteria. Environmental Microbiology, v.7, n.11, p.1673-1685, nov. 2005b. Disponível em: <http://onlinelibrary.wiley.com/doi/10.1111/j.1462-2920.2005.00891.x/pdf>. Acesso em: 31 ago. 2015.

BERG, G. Plant-microbe interactions promoting plant growth and health: perspectives for controlled use of microorganisms in agriculture. Applied Microbiology and Biotechnology, Heidelberg, v.84, n. 1, p. 11 18, ago, 2009. Disponível em:<http://link.springer.com/article/10.1007\%2Fs00253-009-2092-7/ fulltext.html>. Acesso em: 31 ago. 2015. 
BOLTON JUNIOR, H.; FREDRICKSON, J. K.; ELLIOTT, L. F. Microbial ecology of the rhizosphere. In: METTING JUNIOR, F. B. (Eds.). Soil microbial ecology: applications in agricultural and environmental management. New York: Marcel Dekker, 1992. p.27-63.

BRADER, G.; COMPANT, S.; MITTER, B.; TROGNITZ, F.; SESSITSCH, A. Metabolic potential of endophytic bacteria. Current Opinion in Biotechnology, v. 27, p.30-37, jun. 2014. Disponível em:< http:// www.sciencedirect.com/science/article/pii/S0958166913006745 >. Acesso em: 08 ago. 2015.

CABRAL, L.; SIQUEIRA, J. O.; SOARES, C. R. F. S.; PINTO, J. E. B. P. Retenção de metais pesados em micélio de fungos micorrízicos arbusculares. Química Nova, v. 33, n. 1, p. 25-29, 2010. Disponível em: < http://www.scielo.br/pdf/qn/v33n1/05.pdf>. Acesso em: 31 ago. 2015.

CAIRNEY, J. W. G. Ectomycorrhizal fungi: the symbiotic route to the root for phosphorus in forest soils. Plant and Soil, Netherlands, v.344, n.1-2, p.51-71, jul. 2011. Disponível em:<http://link.springer. com/article/10.1007\%2Fs11104-011-0731-0/fulltext.html>. Acesso em: 31 ago. 2015.

CARD, S. D.; TAPPER, B. A.; LOYD-WES.; WRIGHT, K. M. Assesment of fluorescein-based fluorescent dyes for tracing Neotyphodium endophytes in planta. Mycologia, v.105, n.1, p.221-229, 2013. Disponível em:< http://www.mycologia.org/content/105/1/221.short>. Acesso em: 08 ago. 2015.

CHAGAS JÚNIOR, A. F.; OLIVEIRA, L. A. de; OLIVEIRA, A. N de. Caracterização genética de rizóbios isolados de solos no Amazonas baseada na técnica de PCR-RFLP. Semina: Ciências Agrárias, Londrina, v.30, n.4, p.841-846, out./dez. 2009.

CHALK, P. M.; SOUZA, R. F.; URQUIAGA, S.; ALVES, B. J. R.; BODDEY, R. M. The role of arbuscular mycorrhiza in legume symbiotic performance. Soil Biology \& Biochemistry, v.38, n.9, p.2944-2951, set. 2006.

COMPANT, S.; KAPLAN, H.; SESSITSCH, A.; NOWAK, J.; AIT BARKA, E.; CLÉMENT, C. Endophytic colonization of Vitis vinifera L. by Burkholderia phytofirmans strain PsJN: from the rhizosphere to inflorescence tissues. FEMS Microbiology Ecology, Malden, v.63, n.1, p.84-93, jan. 2008. Disponível em: $<$ http://onlinelibrary.wiley.com/doi/10.1111/j.1574-6941.2007.00410.x/pdf>. Acesso em: 31 ago. 2015.

COMPANT, S.; CLÉMENT, C.; SESSITSCH, A. Plant growth-promoting bacteria in the rhizo- and endosphere of plants: Their role, colonization, mechanisms involved and prospects for utilization. Soil Biology \& Biochemistry, v.42, n.5, p.669-678, 2010. Disponível em: < http://www.sciencedirect. com/science/article/pii/S0038071709004398>. Acesso em: 31 ago. 2015.

COMPANT, S.; MITTER, B.; COLLI-MULL, J. G.; GANGL, H.; SESSITSCH, A. Endophytes of grapevine flowers, berries, and seeds: Identification of cultivable bacteria, comparison with other plant parts, and visualization of niches of colonization. Microbial Ecology, Malden, v.62, n.1, p.188-197, jul. 2011. Disponível em:<http://link.springer.com/article/10.1007\%2Fs00248-011-9883-y/fulltext. html>. Acesso em: 31 ago. 2015.

COMPANT, S.; SESSITSCH, A.; MATHIEU, F. The $125^{\text {th }}$ anniversary of the first postulation of the soil origin of endophytic bacteria - a tribute to M.L.V. Galippe. Plant and Soil, Netherlands, v.356, n.1-2, p.299301, jul. 2012. Disponível em:<http://link.springer.com/article/10.1007\%2Fs1 1104-012-1204-9/ fulltext.html>. Acesso em: 31 ago. 2015. 
COOPER, J. E. Multiple responses of rhizobia to flavonoids during legume root infection. Advances in Botanical Research, New York, v.41, p.1-62, 2004.

CORKIDI, L.; BOHN, J.; EVANS, M. Effects of bifenthrin on mycorrhizal colonization and growth of corn. HortTechnology, v.19, n.4, p.809-812, out/dez. 2009. Disponível em:<http://horttech.ashspublications.org/content/19/4/809.full>. Acesso em: 31 ago. 2015.

CZERNIAK, M. J.; STÜRMER, S. L. Produção de inoculante micorrízico on farm utilizando resíduos da indústria florestal. Revista Brasileira de Ciência do Solo, v.38, n.6, p. 1712-1731, 2014.

DENNIS, P. G.; MILLER, A. J.; HIRSCH, P. R. Are root exudates more important than other sources of rhizodeposits in structuring rhizosphere bacterial communities? FEMS Microbiology Ecology, Malden, v.72, n.3, p.313-327, jun. 2010. Disponível em:<http://onlinelibrary.wiley.com/doi/10.1111/j. 1574-6941.2010.00860.x/pdf>. Acesso em: 31 ago. 2015.

DENG, Z.; ZHANG, R.; SHI, Y.; HU, L.; TAN, H.; CAO, L. Enhancement of phytoremediation of $\mathrm{Cd}$ - and $\mathrm{Pb}$-contaminated soils by self-fusion of protoplasts from endophytic fungus Mucor sp. CBRF59. Chemosphere, v. 91, p.41-47, 2013. Disponível em:<http://www.ncbi.nlm.nih.gov/pubmed/23273739>. Acesso em: 31 ago. 2015.

EISENHAUR, N. Aboveground-belowground interactions as a source of complementarity effects in biodiversity experiments. Plant and Soil, Netherlands, v.351, n.1-2, p.1-22, fev. 2012. Disponível em:<http://link.springer.com/article/10.1007\%2Fs11104-011-1027-0/fulltext.html>. Acesso em: 31 ago. 2015.

FAO. Food and Agriculture Organization of the United Nations. 2013. Disponível em: < http://faostat3.fao.org/faostat-gateway/go/to/browse/Q/QC/E> Acesso em: 08 ago. 2014.

FERNÁNDEZ, F.; DELL'AMICO, J. M.; ANGOA, M. V.; PROVIDENCIA, I. E. Use liquid inoculum of the arbuscular mycorrhizal fungi Glomus hoi in rice plants cultivated in a saline Gleysol: A new alternative to inoculate. Journal of Plant Breeding and Crop Science, v.3, n.2, p.24-33, fev. 2011. Disponível em:<http://www.academicjournals.org/article/article1379685609_Fernandez\%20et\%20al.pdf> Acesso em: 08 ago. 2015.

GABRIEL-NEUMANN, E.; NEUMANN, G.; LEGGEWIE, G.; GEORGE, E. Constitutive overexpression of the sucrose transporter SoSUt1 in potato plants increases arburcular mycorrhiza fungal root colonization under high, but not under low, soil phosphorus availability. Journal Plant Physiology, v.168, p.911-919, 2011.

GANGE, A. C.; GANE, D. R. J.; CHEN, Y.; GONG, M. Dual colonization of Eucalyptus urophylla S.T. Blake by arbuscular and ectomycorrhizal fungi affects levels of insect herbivore attack. Agricultural and Forest Entomology, Malden, v.7, n.3, p.253-263, ago. 2005. Disponível em:<http://onlinelibrary.wiley.com/doi/10.1111/j.1461-9555.2005.00268.x/pdf>. Acesso em: 08 ago. 2015.

GARG, N.; CHANDEL, S. Arbuscular mycorrhizal networks: process and functions. A review. Agronomy for Sustainable Development, Paris, v.30, n.2, p.581-599, 2011.

GEWIN, V. Food: An underground revolution. Nature, v. 466, p. 552-553, 2010. Disponível em: <http://www.nature.com/news/2010/100728/full/466552a.html>. Acesso em: 08 ago. 2015. 
HALLMANN, J. Plant interactions with endophytic bacteria. In: JEGER, M.J.; SPENCE, N. J. Biotic interactions in plant-pathogen associations. Wallingford: CABI Publishing, 2001. p.87-119.

HANDELSMAN, J. Metagenomics: Application of Genomics to Uncultured Microorganisms. Microbiology and molecular biology reviews, Washington, v. 68, n. 4, p.669-685, dez. 2004. Disponível em:< http://mmbr.asm.org/content/68/4/669>. Acesso em: 31 ago. 2015.

HARDOIM, P.R.; van OVERBEEK, L.S.; van ELSAS, J. D. Properties of bacterial endophytes and their proposed role in plant growth. Trends in Microbiology, Cambridge, v.16, n.10, p.463-471, out. 2008. Disponível em: http://www.cell.com/trends/microbiology/fulltext/S0966-842X(08)00192-3?large_figure $=$ true . Acesso em: 08 ago. 2015.

HARTMANN, A.; ROTHBALLER, M.; SCHMID, M. Lorenz Hiltner, a pioneer in rhizosphere microbial ecology and soil bacteriology research. Plant and Soil, Netherlands, v.312, n.1-2, p.7-14, nov. 2008. Disponível em: <http://link.springer.com/article/10.1007\%2Fs11104-007-9514-z/fulltext. html>. Acesso em: 08 ago. 2015.

HASHEM, M.; ABO-ELYOUSR, K. A. Management of the root-knot nematode Meloidogyne incognita on tomato with combinations of different biocontrol organisms. Crop Protection, v.30, n.3, p.285-292, mar. 2011.

HERRIDGE, D. F.; PEOPLES, M. B.; BODDEY, R. M. Global inputs of biological nitrogen fixation in agricultural systems. Plant and Soil, Netherlands, v.311, n.1-2, p.1-18, out. 2008. Disponível em: < http:// link.springer.com/article/10.1007\%2Fs11104-008-9668-3/fulltext.html>. Acesso em: 08 ago. 2015.

HINSINGER, P.; BENGOUGH, A. G.; VETTERLEIN, D.; YOUNG, I. M. Rhizosphere: biophysics, biogeochemistry and ecological relevance. Plant and Soil, Netherlands, v.321, n.1-2, p.117-152, ago. 2009. Disponível em:< http://link.springer.com/article/10.1007\%2Fs11104-008-9885-9/fulltext. html>. Acesso em: 31 ago. 2015.

HOFFMANN, D.; VIERHEILIG, H.; PENEDER, S.; SCHAUSBERGER, P. Mycorrhiza modulates aboveground tri-trophic interactions to the fitness benefit of its host plant. Ecological Entomology, Malden, v.36, n.5, p.574-581, 2011. Disponível em:< http://onlinelibrary.wiley.com/doi/10.1111/j. 1365-2311.2011.01298.x/pdf>. Acesso em: 31 ago. 2015.

HUNGRIA, M. Inoculação com Azospirillum brasilense: inovação em rendimento a baixo custo. Londrina: Embrapa Soja, 2011. 36p. (Documentos Embrapa Soja, n. 325)

JAMES, E. K.; GYNESHWAR, P.; MATHAN, N.; BARRAQUI, W. L.; REDDY, P. M.; IANNETTA, P. P.; OLIVARES, F. L.; LADHA, J. K. Infection and colonization of rice seedlings by the plant growth-promoting bacterium Herbaspirillum seropodicae Z67. Molecular Plant-Microbe Interactions, Saint Paul, v.15, n.9, p.894-906, set. 2002. Disponível em:< http://apsjournals.apsnet.org/doi/pdf/10.1094/ MPMI.2002.15.9.894>. Acesso em: 08 ago. 2015.

JOHNSTON-MONJE, D.; RAIZADA, M. N. Conservation and diversity of seed associated endophytes in Zea across boundaries of evolution, ethnography and ecology. PLoS ONE, San Francisco, v.6, n.6, p.122, jun. 2011. Disponível em:< http://www.plosone.org/article/info\%3Adoi\%2F10.1371\%2Fjournal.pone.0020396>. Acesso em: 08 ago. 2015. 
JUMPPONEN, A. Dark septate endophytes - are they mycorrhizal? Mycorrhiza, Heidelberg, v.11, n.4, p.207-211, set. 2001. Disponível em:< http://link.springer.com/article/10.1007\%2Fs005720100112>. Acesso em: 08 ago. 2015.

KASCHUK, G.; KUYPER, T. W.; LEFFELAAR, P. A.; HUNGRIA, M.; GILLER, K. E. Are the rates of photosynthesis stimulated by the carbon sink strength of rhizobial and arbuscular mycorrhizal symbioses? Soil Biology \& Biochemistry, v.41, n.6, p.1233-1244, jun. 2009.

KIRIACHECK, S. G.; AZEVEDO, L. C. B.; PERES, L. E. P.; LAMBAIS, M. R. Regulação do desenvolvimento de micorrizas arbusculares. Revista Brasileira de Ciência do Solo, Viçosa, v.33, n.1, p.1-16, jan/feb. 2009. Disponível em:<http://www.scielo.br/scielo.php?script=sci_arttext\&pid=S0100-06832009000100001>. Acesso em: 08 ago. 2015.

KORANDA, M.; SCHNECKER, J.; KAISER, C.; FUCHSLUEGER, L.; KITZLER, B.; STANGE, C. F.; SESSITSCH, A.; ZECHMEISTER-BOLTENSTERN, S.; RICHTER, A. Microbial processes and community composition in the rhizosphere of European beech - The influence of plant $C$ exudates. Soil Biology \& Biochemistry, v.43, n.3, p.551-558, mar. 2011. Disponível em:< http://www.ncbi.nlm.nih.gov/ pmc/articles/PMC3032887/>. Acesso em: 31 ago. 2015.

LAKOWICZ, J. R. Principles of fluorescence spectroscopy. New York: Springer, 2006. 954p.

LOPES, R. B. A indústria no controle biológico: produção e comercialização de microrganismos no Brasil. In: BETTIOL, W.; MORANDI, M.A.B. Biocontrole de doenças de plantas: uso e perspectivas. Jaguariúna: Embrapa Meio Ambiente, 2009. p.15-28.

LUCERO, M. E.; UNC, A.; COOKE, P.; SUN, S. Endophyte microbiome diversity in micropropagated Atriplex canescens and Atriplex torreyi var griffithsii. PLoS ONE, San Francisco, v.6, n.3, p.1-12, mar. 2011. Disponível em:< http://www.ncbi.nlm.nih.gov/pubmed/21437280>. Acesso em: 31 ago. 2015.

MANDYAM, K.; JUMPPONEM, A. Seeking the elusive function of the root-colonising dark septate endophytic fungi. Studies in Mycology, v.53, n.1, p.173-189, dez. 2005. Disponível em: < http:// www.sciencedirect.com/science/article/pii/S0166061614602293 > . Acesso em: 31 ago. 2015.

MENDES, R.; KRUIJT, M.; BRUIJN, I. de; DEKKERS, E.; VOORT, M. VAN DER; SCHNEIDER, J. H. M.; PICENO, Y. M.; DESANTIS, T. Z.; ANDERSEN, G. L.; PETER A. H. M. B.; RAAIJMAKERS, J. M. Deciphering the rhizosphere microbiome for disease-suppressive bacteria. Science, v.332, p.10971100, 27 mai. 2011. Disponível em:< http://www.sciencemag.org/content/332/6033/1097.short>. Acesso em: 31 ago. 2015.

NEWMAN, L. A.; REYNOLDS, C. M. Bacteria and phytoremediation: new uses for endophytic bacteria in plants. Trends in Biotechnology, v.23, n.1, Jan. 2005. Disponível em: <http://www.sciencedirect.com/science/article/pii/S0167779904003270>. Acesso em: 31 ago. 2015.

NOVAIS, C. B. de; SOUZA, F. A. de; SIQUEIRA, J. O. Caracterização fenotípica e molecular de esporos de fungos micorrízicos arbusculares mantidos em banco de germoplasma. Pesquisa agropecuária brasileira, Brasília, v.45, n.8, p.806-896, ago. 2010. Disponível em:< http://seer.sct.embrapa.br/ index.php/pab/article/view/8203 > . Acesso em: 31 ago. 2015. 
PAWLOWSKI, K. Actinorhizal symbioses. In: LEIGH, G.J. (Ed.). Nitrogen fixation at the millennium. Brighton, Elsevier Science, 2002. p.167-189.

RAJENDHRAN, J.; GUNASEKARAN, P. Strategies for accessing soil metagenome for desired applications. Biotechnology Advances, v.26, p.576-59, 2008. Disponível em: < http://www.ncbi.nlm.nih. gov/pubmed/18786627> . Acesso em: 31 ago. 2015.

RASCHE, F.; LUEDERS, T.; SCHLOTER, M.; SCHAEFER, S.; BIEGGER, F.; GATTINGER, A.; HOOD-NOWOTNY, R. C.; SESSITSCH, A. DNA-based stable isotope probing enables the identification of active bacterial endophytes in potatoes. New Phytologist, v.181, n.4, p.802-807, mar. 2009. Disponível em: < http://www.ncbi.nlm.nih.gov/pubmed/19140937 >. Acesso em: 31 ago. 2015.

REINHOLD-HUREK, B.; HUREK, T. Living inside plants: bacterial endophytes. Current Opinion in Plant Biology, v.14, n.4, p.435-443, ago. 2011.

RODRIGUEZ, R. J.; HENSON, J.; VOLKENBURG, E.; HOY, M.; WRIGHT, L.; BECKWITH, F.; KIM, Y.; REDMAN, R. S. Stress tolerance in plants via habitat-adapted symbiosis. The International Society for Microbial Ecology Journal, v.4, n.4, p.404-416, abr. 2008. Disponível em:< http://www.nature. com/ismej/journal/v2/n4/full/ismej2007106a.html>. Acesso em: 31 ago. 2015.

RODRÍGUEZ-ROMERO, A. S.; JAIZME-VEGA, M. C. Assessment of the effect of commercial mycorrhizal fungi products on the growth of banana plants in the nursery. InfoMusa, v.16, n.1-2, p.23-27, jun/dec. 2007.

ROSSI, M. J. Tecnologia para produção de inoculantes de fungos ectomicorrízicos utilizando cultivo submerso em biorreator Airlift. 2006. 188 p. Tese (Doutorado em Engenharia química) - Universidade Federal de Santa Catarina, Florianópolis, 2006.

RYAN, R. P.; MONCHY, S.; CARDINALE, M.; TAGHAVI, S.; CROSSMAN, L.; AVISON, M. B.; BERG, G.; LELIE, D.; DOW, J. M. The versatility and adaptation of bacteria from the genus Stenotrophomonas. Nature Reviews Microbiology, v.7, n.7, p.514-525, jul. 2009. Disponível em:< http://www. nature.com/nrmicro/journal/v7/n7/full/nrmicro2163.html>. Acesso em: 31 ago. 2015.

SALA, V. M. R.; FREITAS, S. dos S.; SILVEIRA, A. P. D. Interação entre fungos micorrízicos e bactérias diazotróficas em trigo. Pesquisa Agropecuária Brasileira, Brasília, v.42, n.11, p.1593-1600, nov. 2007. Disponível em: http://www.scielo.br/scielo.php?pid=S0100=204-2007001100011X\&scriptsci_arttext>. Acesso em: 31 ago. 2015.

SCHULTZ, B.; BOYLE, C. The endophytic continuum. Mycological Research, v.109, n.6, p.661686 , jun. 2005.

SENTHILKUMAR, M.; MADHAIYAN, M.; SUNDARAM, S. P.; KANNAIYAN, S. Intercellular colonization and growth promoting effects of Methylobacterium sp. with plant-growth regulators on rice (Oryza sativa L. Cv C0-43). Microbiological Research, v.164, n.1, p.92-104, jan. 2009. Disponível em:< http:// www.sciencedirect.com/science/article/pii/S0944501306001315>. Acesso em: 31 ago. 2015.

SILVA, S.; SIQUEIRA, J. O.; SOARES, C. R. F. S. Fungos micorrízicos no crescimento e na extração de metais pesados pela braquiária em solo contaminado. Pesquisa Agropecuária Brasileira, v. 41, n. 12, p. 1749-1757, 2006. Disponível em:<http://www.scielo.br/pdf/pab/v41n12/a09v4112.pdf>. Acesso em: 31 ago. 2015. 
SIQUEIRA, J. O.; POUYÚ, E.; MOREIRA, F. M. S. Micorrizas arbusculares no crescimento pós-transplantio de mudas de árvores em solo com excesso de metais pesados. Revista Brasileira de Ciência do Solo, v.23, p.569-580, 1999. Disponível em:<http://sbcs.solos.ufv.br/solos/revistas/v23n3a10. pdf>. Acesso em: 31 ago. 2015.

SOLEIMANI, M.; HAJABBASI, M.; AFYUNI, M.; MIRLOHI, A.; BORGGAARD, O. K.; HOLM, P. E. Effect on endophytic fungi on cadmium tolerance and bioaccumulationby Festuca arundinacea and Festuca pratensis. International Journal of Phytoremediation, v. 12, n. 6, p. 535-549, 2010. Disponível em:<http://www.ncbi.nlm.nih.gov/pubmed/21166279>. Acesso em: 31 ago. 2015.

SULZBACHER, M. A. Fungos ectomicorrízicos do Sul do Brasil, com ênfase no hábito hipógeo. 2010. 129 f. Dissertação (Mestrado em Ciência do solo) -Universidade Federal de Santa Maria, Santa Maria, 2010.

SVISTOONOFF, S.; LAPLAZE, L.; LIANG, J.; RIBEIRO, A.; GOUVEIA, M. C.; AUGUY, F.; FEVEREIRO, P.; FRANCHE, C.; BOGUSZ, D. Infection-related activation of the cg12 promoter is conserved between actinorhizal and legume-rhizobiaroot nodule symbiosis. Plant Physiology, Waterbury, v.136, n.2, p.3191-3197, out. 2004. Disponível em:< http://www.plantphysiol.org/content/136/2/3191. full>. Acesso em: 31 ago. 2015.

THOMAS, P.; REDDY, K. M. Microscopic elucidation of abundant endophytic bacteria colonizing the cell wall-plasma membrane peri-space in the shoot-tip tissue of banana. AoB Plants, 2013. Disponível em:< http://aobpla.oxfordjournals.org/content/5/plt011.full.pdf+html>. Acesso em: 31 ago. 2015.

THOMAS, P.; SEKHAR, A. C. Live cell imaging reveals extensive intracellular cytoplasmatic colonization of banana by normally non-cultivable endophytic bacteria. AoB Plants, 2014. Disponível em: < http://aobpla.oxfordjournals.org/content/6/plu002.full.pdf+html>. Acesso em: 31 ago. 2015.

TRAJANO, M. A. B.; KASUYA, M. C.; TOTOLA, M. R.; BORGES, A. C.; NOVAIS, R. F. Suprimento de fósforo e formação de micorrizas em mudas de eucalipto em sistema de raízes divididas. Revista Árvore, Viçosa, v.25, n.2, p.192-201, 2001.

VÁGI, P.; KNAPP, D. G.; KÓSA, A.; SERESS, D.; HORVÁTH, A.; KOVÁCS, G. M.

Simultaneous specific in planta visualization of root-colonizing fungi using fluorescence in situ hybridization (FISH). Mycorrhiza, v.24, p.259-266, 2014. Disponível em: <http://link.springer.com/ article/10.1007\%2Fs00572-013-0533-8>. Acesso em: 31 ago. 2015.

VERESOGLOU, S. D.; RILLING, M. C. Supression of fungal and nematode plant pathogens through arbuscular mycorrhizal fungi. Biology Letters, London, n.8, p.214-217, apr/jun. 2012.

VIEIRA, R. F. Diversidade e taxonomia de rizóbio. In: SILVEIRA, A.P.D. da.; FREITAS, S.S. Microbiota do solo e qualidade ambiental. Campinas: Instituto Agronômico, 2007. p.165-192.

XAVIER, L. J. C.; GERMIDA, J. J. Selective interactions between arbuscular mycorrhizal fungi and Rhizobium leguminosarum bv. viceae enhance pea yield and nutrition. Biology and Fertility Soil, v.37, n.3, p.261-267, mar. 2003. Disponível em:< http://link.springer.com/article/10.1007\%2Fs00374-003-0605-6/fulltext.html> Acesso em: 31 ago. 2015. 
ZABIHI, H.R.; SAVAGHEBI, K.; KHAVAZI, A.; GANJALI, M.; MIRANSARI, M.

Pseudomonas bacteria and phosphorous fertilization, affecting wheat (Triticum aestivum L.) yield and P uptake under greenhouse and field conditions. Acta Phisiologiae Plantarum, v.33, n.1, p.145-152, jan. 2011. Disponível em:< http://link.springer.com/article/10.1007\%2Fs11738-010-0531-9/fulltext.html>. Acesso em: 31 ago. 2015.

WAGG, C.; PAUTLER, M.; MASSICOTTE, H. B.; PETERSON, R. L. The co-occorrence of ectomycorrhizal, arbuscular mycorrhizal, and dark septate fungi in seedlings of four members of the Pinaceae. Mycorrhiza, Heidelberg, v.18, n.2, p.103-110, fev. 2008. Disponível em:<http://link.springer.com/ article/10.1007\%2Fs00572-007-0157-y/fulltext.html>. Acesso em: 31 ago. 2015.

WALKER, T. S.; BAIS, H. P.; GROTEWOLD, E.; VIVANCO, J. M. Root exudation and rhizosphere biology. Plant Physiology, Waterbury, v.132, n.1, p.44-51, mai, 2003. Disponível em:<http://www. plantphysiol.org/content/132/1/44.full>. Acesso em: 31 ago. 2015.

WANG, B.; QIU, Y. L. Phylogenetic distribuition and evolution of mycorrhizas in land plants. Mycorrhiza, Heidelberg, v.16, n.5, p.299-363, jul. 2006. Disponível em:< http://link.springer.com/ article/10.1007\%2Fs00572-005-0033-6/fulltext.html>. Acesso em: 31 ago. 2015.

\section{Histórico editorial}

Submetido em: 09/02/2014

Aceito em: 30/10/2014 